\title{
DESENVOLVIMENTOS NA PRODUÇÃO DE GUSA - VISÃO ARCELORMITTAL AÇOS PLANOS AMÉRICA DO SUL*
}

\author{
Jorge Luiz Ribeiro de Oliveira ${ }^{1}$ \\ Francisco Coutinho Dornelas ${ }^{2}$ \\ Jorge Adelino de Faria ${ }^{3}$ \\ Erick Torres Bispo dos Santos ${ }^{4}$ \\ Edson Luiz Massonori Harano 5
}

\section{Resumo}

A indústria siderúrgica na América do Sul tem sido desafiada desde a crise econômica mundial do final de 2008, como as demais siderúrgicas ao redor do mundo. O cenário de continua degradação das matérias primas, em especial o minério de ferro e a necessidade de reduzir custos, considerando que cerca de $70 \%$ do mesmo está relacionado à produção de gusa, atuando em direção oposta, torna este desafio maior ainda. Operar um Alto Forno com elevadas taxas de injeção de carvão (mais que $180 \mathrm{~kg} / \mathrm{t}$ de gusa) e baixo taxa de combustíveis (menor que 490 $\mathrm{kg} / \mathrm{t}$ de gusa), considerando a elevação da taxa de geração de escória devido a matéria prima em degradação $(\sim 300 \mathrm{~kg} / \mathrm{t}$ de gusa) torna-se obrigatório ter estabilidade operacional por meio de boas práticas operacionais suportado por adequado sistema de manutenção centrado em confiabilidade (RCM). Este trabalho objetiva mostrar como a ArcelorMittal planta de Tubarão está enfrentando esta situação, visando atingir os objetivos citados anteriormente.

Palavras-chave: Ferro gusa; Alto forno; RCM; Coque rate.

\section{DEVELOPMENTS IN IRONMAKING - OVERVIEW OF ARCELORMITTAL FLAT CARBON SOUTH AMERICA}

\section{Abstract}

The South America Steel Industry is being challenged since the last 2008 financial crisis, as the others plants around the world. The scenario of ferrous raw material continuously being downgrading and the necessity to reduce production cost to be competitive, providing that around $70 \%$ of crude steel cost is related to hot metal, is in the opposite direction and makes the challenge be tougher.

To operate a blast furnace with high coal injection (more than $180 \mathrm{~kg} / \mathrm{t}$ of HM) and low fuel rate (less than $490 \mathrm{~kg} / \mathrm{t}$ ), facing the slag rate increasing due to raw material downgrading as mentioned before $(\sim 300 \mathrm{~kg} / \mathrm{t})$ is mandatory to have operational stability through good operational practices supported by an adequate reliability centered maintenance (RCM). The aim of this lecture is to show the main ongoing actions at ArcelorMittal Tubarao in order to achieve such.

Keywords: Ironmaking; Blast furnace; RCM; Coke ratel.

1 Engenheiro Metalurgista, COO da ArcelorMittal Aço Plano da América do Sul, Serra, ES Brasil.

2 MSc e Engenheiro Metalurgista, assessor sênior do CEO, ArcelorMittal Aço Plano da América do Sul, Serra, ES Brasil.

3 Engenheiro Metalurgista, Gerente de Controle de Processo da Área de Gusa e Energia, ArcelorMittal Tubarao, Serra, ES Brasil.

4 MSc e Engenheiro Metalurgista, assessor sênior do COO, ArcelorMittal Aço Plano da América do Sul, Serra, ES Brasil.

5 Engenheiro de Minas, Consultor para o Departamento de Produção de Gusa, ArcelorMittal Tubarao, Serra, ES Brasil. 


\section{INTRODUÇÃO}

A produção mundial de Aço aumentou 1,8\% em 2014 e cerca de $50 \%$ deste total foi produzido na China, a América do Sul em torno de 3\% e o Brasil produziu mais de $70 \%$ desta região. Em 2014, a produção de aço da América do Sul reduziu 1,6\%, principalmente pela redução na Venezuela e Chile. Na Tabela 1 são mostrados os detalhes numéricos.

Tabela 1. Produção de Aço Bruto na América Latina

\begin{tabular}{|c|c|c|c|c|c|c|c|}
\hline \multirow{2}{*}{ País } & \multicolumn{2}{|c|}{ JAN/NOV } & \multirow{2}{*}{$\begin{array}{c}14 / 13 \\
(\%)\end{array}$} & \multirow{2}{*}{$\begin{array}{l}\text { OUT } \\
2014\end{array}$} & \multicolumn{2}{|c|}{ NOVEMBER } & \multirow{2}{*}{$\begin{array}{c}14 / 13 \\
(\%)\end{array}$} \\
\hline & 2014 & 2013 & & & 2014 & 2013 & \\
\hline BRASIL & 31.284 & 31.508 & $(0,01)$ & 3.052 & 2.677 & 2.707 & $(1,1)$ \\
\hline MÉXICO & 17.818 & 16.666 & 6,9 & 1.658 & 1.741 & 1.442 & 20,7 \\
\hline ARGENTINA & 5.042 & 4.752 & 6,1 & 478 & 461 & 469 & $(1,7)$ \\
\hline VENEZUELA & 1.336 & 2.052 & $(34,9)$ & 161 & 142 & 97 & 46,4 \\
\hline COLÔMBIA & 1.154 & 1.184 & $(2,5)$ & 114 & 120 & 123 & $(2,4)$ \\
\hline CHILE & 1.024 & 1.225 & $(16,4)$ & 98 & 93 & 107 & $(13,1)$ \\
\hline PERU & 1.034 & 974 & 6,2 & 105 & 110 & 89 & 23,6 \\
\hline EQUADOR & 612 & 522 & 17,2 & 65 & 49 & 47 & 4,3 \\
\hline TRINIDAD-TOBAGO & 527 & 512 & 2,9 & 58 & 60 & 59 & 1,7 \\
\hline CENTRAL AMERICA & 461 & 449 & 2,7 & 50 & 52 & 51 & 2,0 \\
\hline CUBA & 296 & 287 & 3,1 & 32 & 34 & 33 & 3,0 \\
\hline URUGUAI & 83 & 81 & 2,5 & 10 & 10 & 10 & 0,0 \\
\hline PARAGUAI & 42 & 40 & 5,0 & 5 & 5 & 5 & 0,0 \\
\hline LATIN AMERICA TOTAL & 60.713 & 60.252 & 0,8 & 5.886 & 5.554 & 5.239 & 6,0 \\
\hline SOUTH AMERICA TOTAL & 42.895 & 43.586 & $(1,59)$ & 4.228 & 3.813 & 3.797 & 0,4 \\
\hline
\end{tabular}

Obviamente o custo de produção é um dos mais importantes Indicadores de Performance, não sendo diferente na Indústria Siderúrgica, e especialmente nos últimos 5 anos, como foi mencionado, o custo de produção de gusa é muito importante e preponderante (cerca de $70 \%$ do custo do aço bruto). Todos os esforços que trazem redução de custo são sinônimos de aumento de competitividade, conseguindo assim mesmo aumentar a produção das unidades operativas

Alternativas para redução do custo do gusa são perseguidas, e dentre os métodos tradicionais que trazem resultados com impacto positivo, um dos mais importantes é a redução do consumo específico de combustível e substituição do coque pela injeção de carvão. Outro método consiste na otimização das cargas metálicas dos Altos Fornos focando o processo, como exemplo a redução do Volume de Escória.

A melhoria da performance produtiva está fortemente associada à maior disponibilidade dos equipamentos e estabilidade do processo que possibilitam conduzem ao consumo específico de combustíveis a valores bem baixos. Por último, mas não menos importante para o sucesso destas iniciativas são as pessoas bem capacitadas, como será abordado neste trabalho.

\section{MATERIAIS E MÉTODOS}

\subsection{Matérias Primas para os Altos Fornos}

Com relação às matérias-primas para os Altos Fornos a Coque das Usinas Siderúrgicas Brasileiras, serão descritos algumas informações, inicialmente sobre as cargas ferríferas e posteriormente sobre os Combustíveis. 


\subsubsection{Cargas ferríferas}

O elemento principal das cargas ferríferas dos Altos Fornos era o Sinter até o final da década de 1990, onde a maioria dos Altos Fornos operava somente com Sinter e Minérios Granulados. Quando iniciou a operação do AF №2 da AMT (ArcelorMittal Tubarão), foi decidido manter a produção de Sinter e introduzir a Pelota para o complemento da carga, participando com cerca de 20 a 25\% da carga. Em 2007 partiu-se o AF No3 da AMT, incrementando a participação da Pelota para $40 \%$ a $50 \%$ da carga. Outras siderúrgicas brasileiras mantiveram o Sinter e o Minério Granulado como componentes principais da carga, complementando com Pelota numa proporção abaixo de $10 \%$.

Em torno de 2005 iniciou-se a deterioração da qualidade dos minérios destinados às Sinterizações devido ao processo de exaustão das minas localizadas no Quadrilátero Ferrífero, estado de Minas Gerais, onde estão os produtores e fornecedores de minérios para as Usinas Siderúrgicas Integradas, que estão localizadas na região Sudeste do Brasil. Foi observado simultaneamente, o afinamento granulométrico dos Sinter-feeds, bem como a elevação do teor de SiO2, conforme mostrado na figura 1 .

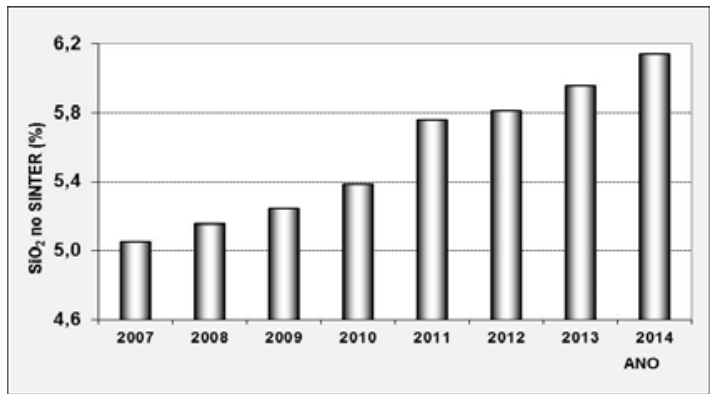

Figura 1 Evolução do teor de $\mathrm{SiO}_{2}$ do Sinter das 7 Usinas Brasileiras

A consequência foi a deterioração da produtividade mostrada na figura 2 , demandando ações corretivas que incrementaram os custos, tais como aumento da taxa de cal virgem e elevação do consumo específico de combustíveis.

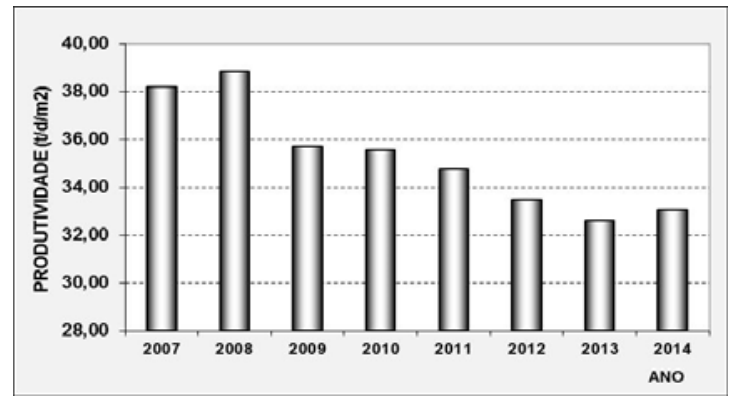

Figura 2 Evolução da Produtividade de Sinter das 7 Usinas Brasileiras

A elevação do teor de $\mathrm{SiO}_{2}$ do Sinter tem impactado diretamente no Volume de Escória gerado nos Altos Fornos, mostrado na figura 3. O processo de deterioração dos Sinter feeds tem continuado anualmente. 


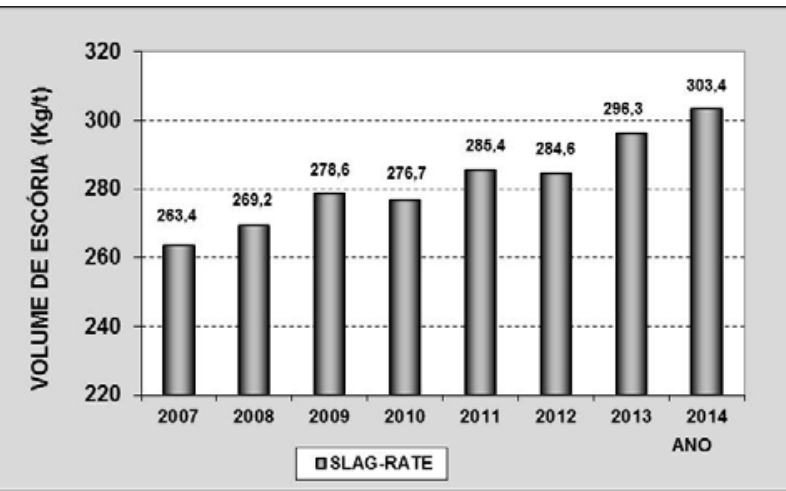

Figura 3. Evolução do Volume de Escória dos Altos Fornos das 7 Usinas Brasileiras

Visando manter a produtividade de Sinter num cenário de deterioração crescente do Sinter Feed, muitos desenvolvimentos foram conduzidos no processo de aglomeração a frio, como exemplo, o processo HPS (Processo hídrido de Pelotização e Sinterização), introdução de Misturadores Intensivos e outros estudos em andamento. Para neutralizar o incremento de $\mathrm{SiO}_{2}$ no Sinter feed, muitos esforços têm sido feito, principalmente pela introdução de Pellet Feed que apresenta teor muito baixo de $\mathrm{SiO}_{2}$, porém o grande desafio é de conseguir resultado de aglomeração a frio adequado, sabendo que este tipo minério para o processo de Sinterização afeta significativamente para menor a produtividade, face a granulometria mais fina.

Enquanto o desenvolvimento para introdução do minério concentrado (Pellet Feed) continua, muitos Altos Fornos têm alteradas as composições das cargas ferríferas, diminuindo Sinter e aumentando Pelotas e/ou Minério Granulado, visando controle do Volume de Escória principalmente. Há também algumas Usinas Siderúrgicas que reduziram a Produtividade de Sinter devido a baixa qualidade dos Sinter feeds e restrições do teor de $\mathrm{SiO}_{2}$ no Sinter que causariam excesso de Volume de Escória nos Altos Fornos, como mostrada na figura 3. Outro catastrófico impacto é o incremento no consumo específico de combustíveis em torno de $20 \mathrm{~kg} / \mathrm{t}$ (figura 4), na mesma direção do incremento do Slag Rate. Este fenômeno é facilmente compreendido: quanto mais elevado o Volume de Escória, maior a necessidade de input de calor.

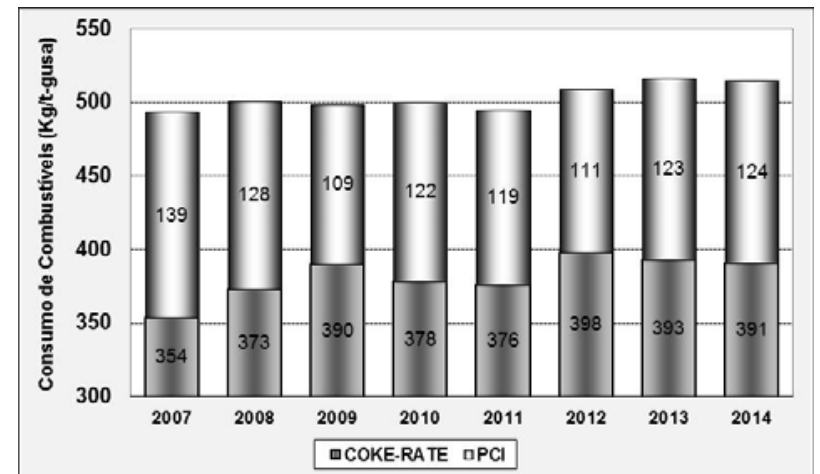

Figura 4 Evolução dos consumos de combustíveis nos Altos Fornos das 7 Usinas Brasileiras 


\subsubsection{Combustíveis sólidos}

\subsubsection{Dependências das baterias de coque}

No mundo inteiro, há um grande interesse no desenvolvimento de tecnologias para reduzir ou até eliminar a dependência da baterias de coque para produção de gusa líquido, entre elas, Processos de Redução Direta, "Smelting", Corex, etc.

Entretanto, o desenvolvimento destas tecnologias em escala industrial ainda requer tempo para consolidar o conhecimento e considerável investimento em pesquisa para o aprimoramento técnico.

Obviamente, o Coque é referenciado como o permeabilizador da carga do Alto Forno, função esta que não é possível ser assumida por outro combustível, uma vez que é o único material capaz de manter a permeabilidade do leito para o gás ascendente e o metal líquido descendente. O coque permanece no estado sólido sob condição de elevada temperatura no Alto Forno, submetido aos diversos níveis de resistência requisitados no interior do reator. Isto permite manter uma distribuição granulométrica bem adequada para a boa permeabilidade, sem o qual seria impossível a produção de gusa líquido [1].

\subsubsection{Injeção de carvão pulverizado}

Os balanços químico e térmico podem ser exercidos parcialmente por combustíveis líquidos (óleo combustível de petróleo, alcatrão), gases de elevado poder calorífico (gás redutor, gás natural e gás de coqueria) ou sólido (especialmente finos de carvão), injetados no Alto Forno através das ventaneiras. Assim, estes combustíveis auxiliares participam como fonte de calor e gás redutor do processo.

$\mathrm{Na}$ década de 1960, o óleo combustível e em alguns casos o gás natural apareceram como os combustíveis ideais para este propósito, considerando o seu baixo custo e elevada disponibilidade. A injeção de óleo combustível foi frustrada pelas crises de petróleo e problemas ambientais. O Gás Natural ainda é aplicável em algumas situações onde há uma considerável massa disponível com preço competitivo para o consumo. Durante este período, outros combustíveis continuaram a serem desenvolvidos e testados, especialmente a injeção de carvão pulverizado. Neste cenário econômico, as vantagens de injeção de combustíveis pelas ventaneiras tornaram-se menos atratavias, e como foi relatado, a injeção de carvão mostrou-se a melhor solução e desde então tem sido praticado na maioria das operações dos Altos Fornos.

O preço do coque no mercado mundial é cerca de 2 vezes mais elevado que o carvão injetado através das ventaneiras, uma vez que a mistura de carvão mineral utilizada como matéria-prima para a produção de coque tem que possuir características especiais que os encarece. Além disso o processo de produção de coque agrega custo. Considerando o custo em particular, tem se procurado carvões que possibilitam altas taxas de substituição de coque.

Brevemente, abaixo são citadas as principais vantagens da injeção de carvão [2]:

- Redução do custo do combustível;

- Redução de custo de investimento em casos de plantas de coqueria novas;

- Aumento da estabilidade operacional do Alto Forno;

- Melhoria das condições ambientais;

- Possível uso de carvão não coqueificáveis;

- Possível incremento de produção de gusa.

Quando o carvão pulverizado é injetado através das ventaneiras para o interior do Alto Forno, o tempo disponível para a combustão é de poucos milissegundos. Ao 
passo que o comprimento da zona de combustão é em torno de $1,5 \mathrm{~m}$ e a velocidade do ar ao redor de $200 \mathrm{~m} / \mathrm{s}$, o tempo de residência das partículas de carvões na zona de combustão varia entre $20 \mathrm{~ms}$ a $30 \mathrm{~ms}$. Se o carvão injetado não possuir características que permita uma eficiente combustão nestas condições, as partículas não queimadas poderão misturar com a escória e sérios problemas operacionais poderão surgir, tais como piora do fluxo gasoso no reator com incremento do número de arriamentos e engaiolamentos, que poderão levar as catastróficas falhas na região das ventaneiras ("raceway"). Na figura 5 é ilustrada a representação destas zonas do Alto Forno e na figura 6 é enfatizada as zonas de combustão e coesiva, onde as partículas não queimadas do carvão e a cinza resultam do processo de combustão dos carvões.

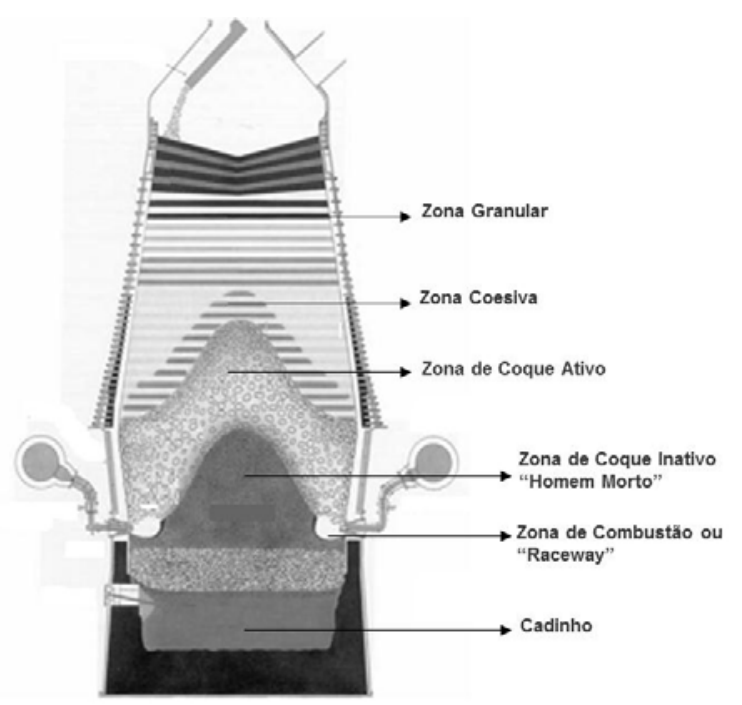

Figura 5. Figura esquemática de um Alto Forno[1].

Para o cenário de custo mencionado, a operação com elevada taxa de injeção (maior que $180 \mathrm{~kg} / \mathrm{t}$ ) parece como uma boa solução que afeta diretamente o resultado financeiro da empresa. $O$ controle rigoroso de qualidade das matériasprimas e operação estável são absolutamente essenciais para atingir esta operação.

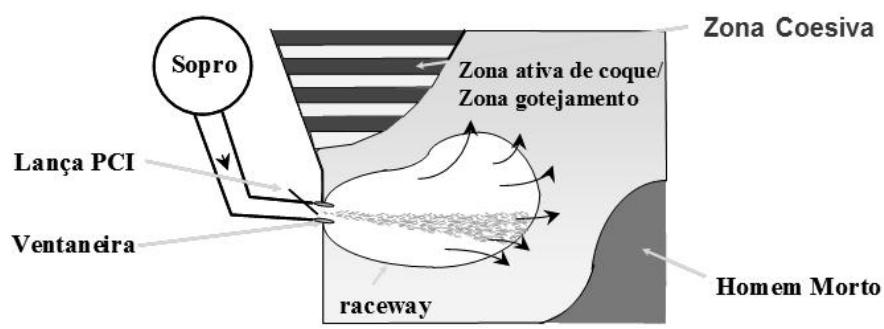

Figura 6 Desenho esquemático da Zona de Comubstão/"Raceway" em evidência, de acordo com o Mathieson et ali (2003) [3]

Visando assegurar uma operação estável do Alto Forno com elevada taxa de injeção de carvão pulverizado, mesmo num cenário de deterioração de qualidade da carga ferrífera, os Altos Fornos Brasileiros tem adotado a filosofia de produzir coque de elevada resistência física, elevada resistência após reação (CSR - Fig.7) e baixa reatividade $(\mathrm{CRI})$.

A principal razão de se manter Coque de elevada qualidade é para assegurar uma boa permeabilidade de toda a coluna de carga e zona coesiva do Alto Forno que possibilitam elevada produtividade com elevada taxa de injeção de carvão. 




Figura 7 Evolução do CSR das 5 Usinas Brasileiras

\section{RESULTADOS E DISCUSSÃO}

\subsection{ArcelorMittal Brasil - Aços Planos}

A Siderúrgica de Tubarão, localizada no município da Serra/ES, é uma Usina Siderúrgica integrada, com capacidade nominal de 7 milhões de toneladas anuais, sendo $57 \%$ de laminado a quente numa Laminação de Tira a Quente compacta, o restante é exportado na forma de placas. A Usina opera com uma Sinterização (6,5Mta), três Baterias de Coqueria Convencional (2,4Mta), quatro Baterias de Coque de Recuperação de Calor (2,2Mta), três Altos Fornos (3,7 Mta, 2,9Mta e 1,2Mta), uma Aciaria com 3 Convertedores (315t/corrida), dois desgaseificadores a vácuo, três lingotamento contínuos com dois veios em cada, uma Laminação de Tiras a Quente $(4,0 \mathrm{Mta})$. O complexo de Laminação a Frio,localizado no município de São Francisco do Sul/SC compreende uma linha de decapagem contínua acoplada ao trem contínuo de Laminador de Tira a Frio com 4 cadeiras (1,4 Mta). Possui ainda 2 linhas de Galvanização de Imersão à quente (0,9 Mta), Fornos de Recozimento, um Laminador de Encruamento e uma linha de Inspeção, a figura 8 resume a essa configuração.

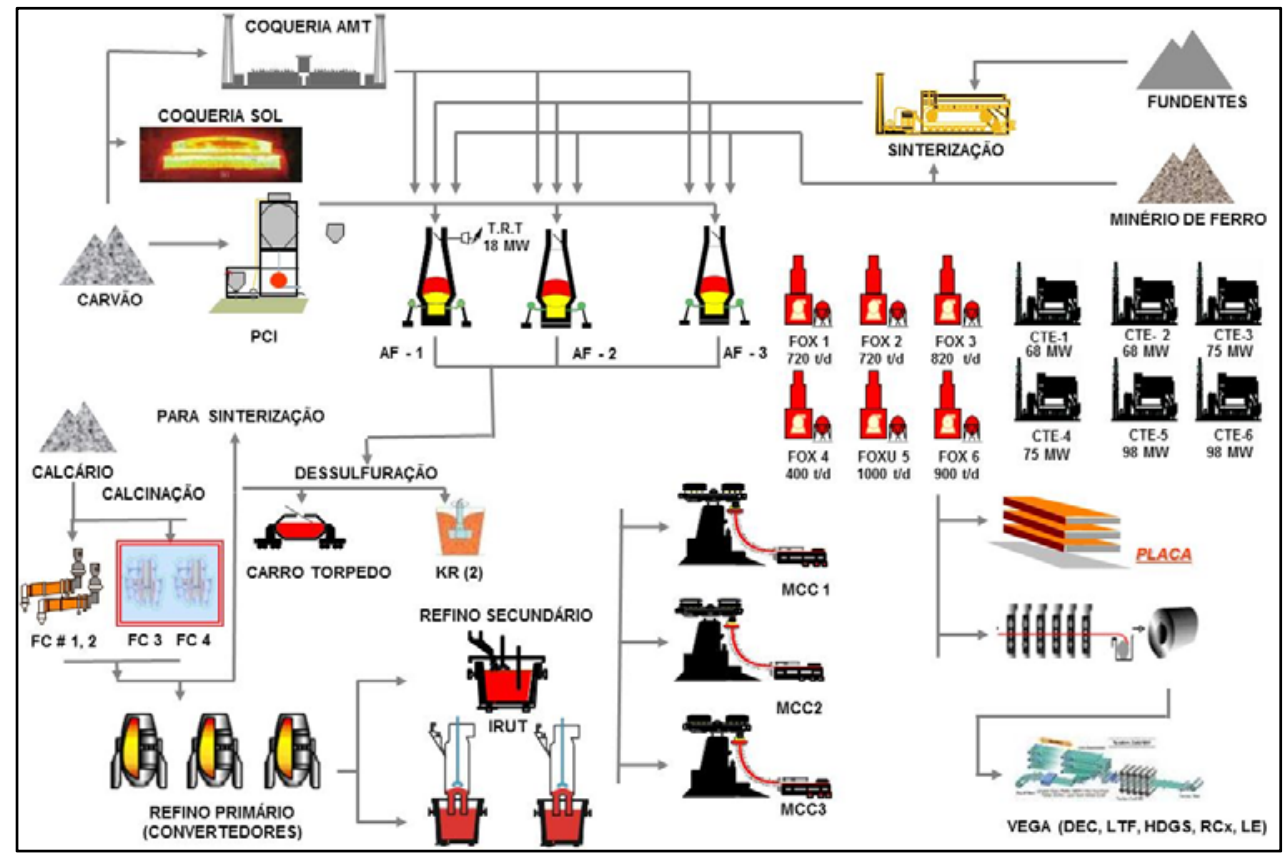

Figura 8 ArcelorMittal Tubarão Aços Planos: Fluxo Esquemático de Produção 


\subsubsection{Principais resultados da Área de Gusa}

É necessário ter em mente que a matriz de matérias-primas (pelota versus minério granulado versus sínter) para operação do Alto Forno varia de Usina para Usina e dependem das circunstâncias específicas de cada negócio. Ser criativo suficiente para adaptar a estes ambientes, mantendo o processo estável ao custo competitivo é um enorme desafio. No caso da ArcelorMittal Tubarão, diversas contramedidas têm sido tomadas para tratar das condições adversas das matérias-primas para obter elevada taxa de injeção de carvão pulverizado (PCl) e consumo específico de combustível num nível apropriado.

$\mathrm{O}$ incremento do teor de $\mathrm{SiO}_{2}$ nos minério de ferro para sinterização (Sinter Feed) e suas consequências, como mencionado anteriormente neste trabalho no item 2.1.1., ocorreu na AM Tubarão, conforme pode ser observado na Figura 9. As contramedidas foram as ações para melhoria da qualidade do coque (elevação do CSR), mudança na matriz da carga ferrífera, ações adicionais de intensiva monitoração e controle de processo operacional pelo time técnico da área de Gusa mostraram-se eficientes, podendo notar um progresso significativo nos últimos 6 meses (Figura 9) nos resultados de consumo específico de coque. Os sumários dos resultados são apresentados na Figura 9.

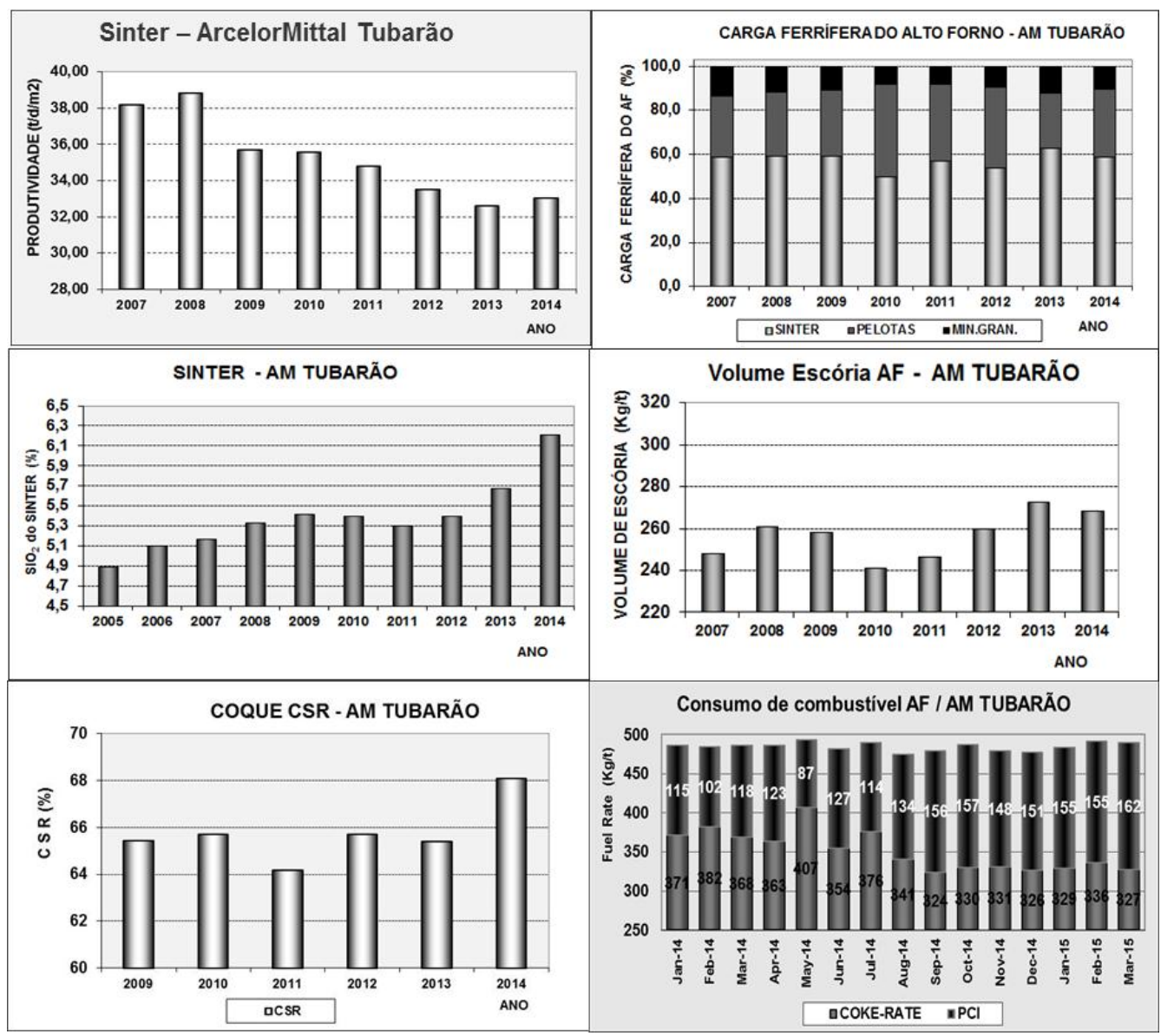

Figura 9: Resultados dos Principais Indicadores gerenciados na área de Gusa

\subsubsection{Manutenção centrada em confiabilidade (RCM)}

Uma boa e estável operação requer os equipamentos em boa forma. Em outras palavras, os equipamentos também são afetados por más práticas.

Para gerenciar adequadamente a manutenção dos principais ativos, diversos ferramentas e sistemas tem sido desenvolvido ao longo da história. 
RCM é um deles. Os objetivos do RCM são para cada sistema identificar os modos de falha e suas consequências e determinar o mais efetivo em custo e aplicar técnicas de manutenção para minimizar o risco e impacto da falha. Isto permite a funcionalidade do sistema e dos equipamentos para serem manutenidos de uma maneira mais econômica, oferecendo as condições necessárias para time operacional perseguir a otimização do processo.

Os objetivos específicos do RCM [4] são:

- Assegurar a realização de inerente segurança a níveis de inerente confiabilidade dos equipamentos

- Reestabelecer os equipamentos a estes níveis inerentes quando ocorrem as deteriorações.

- Obter as informações necessárias para as melhorias dos projetos destes itens nos locais onde a inerente confiabilidade prova estar inadequada.

- Atingir essas metas, a um custo total mínimo, incluindo custos de manutenção, os custos correlatos e consequências econômicas das falhas operacionais.

Neste contexto, depois de balancear a planta, será possível chegar a um bom nível de custo total e trazer a manutenção a nível de excelência. (Figura 10).



Figura 10: Relação entre performance do negócio, dispêndio para manutenção e quartil relativo.

Com o objetivo de atingir esta excelência mencionada, a ArcelorMittal Brasil Aços Planos estabeleceu um plano geral de manutenção no final de 2013, que ligam a estratégia de negócios com os objetivos para curto, médio e longo termo. Um dos principais pilares para suportar tal plano são os recursos humanos. Neste contexto, as competências necessárias foram revisadas para cada função e elencadas os treinamentos adicionais.

As principais premissas foram:

i) Revisão dos padrões das matrizes de treinamentos;

ii) Treinamento de 150 supervisores na metodologia RCM;

iii) Intenso uso de instrutores internos (como treinadores, a baixo custo);

iv) Focado nas áreas com alta incidência de falhas;

v) Treinamentos curtos e práticos;

vi) Treinamento personalizado, focando em competências de baixa habilidade;

vii) Plano de "follow up" através de auditagens específicas. 
Para assegurar o "follow up", diferentes indicadores corporativos (KPIs) foram estabelecidos, para medir a evolução da manutenção e o processo em si, de modo que cada gerente possa controlar o seu setor. O plano está em curso num nível bastante intenso, com atividades até 2017 e um dos resultados preliminares pode ser visto através de KPI da taxa de parada para manutenção não planejada do Alto Forno, onde na AM Tubarão, o resultado caiu de 1,3\% obtido em 2012 para 0,7\% em 2014. Este resultado ainda está longe do melhor resultado "Benchmark" de $0,2 \%$, indicando que há um trabalho árduo a frente.

\subsubsection{Capital humano - investimento}

Capital humano pode ser definido como uma medida do valor econômico de conjunto de habilidades de um empregado. Esta medida tem por base o "input" de produção básica de medida de trabalho, onde todo o trabalho é pensado para ser igual. O conceito de capital humano reconhece que nem todo trabalho é igual e que a qualidade dos empregados pode ser melhorada através de investir neles. A educação, experiência e habilidades de um empregado tem um valor econômico para os empregados e para a economia como um todo.

As pessoas são os ativos mais importantes da empresa, e são extremamente importantes para promover mudanças em uma organização, são eles que administram e governam a empresa, eles executam, controlam as atividades e processos, a empresa é um organismo vivo e as pessoas em que estão inseridos promovem as transformações e melhoraram a empresa, tomando as decisões necessárias para atingir o sucesso.

Se as pessoas são responsáveis por alterações em uma organização, devem ser bem preparado, em seguida, investir em desenvolvimento de pessoas é a chave para o desenvolvimento organizacional. Mudanças de comportamentos devem envolver todos os gerentes, começando com o presidente da empresa e estender a outros líderes; gerentes treinados para entender e buscar em sua equipe de trabalho potenciais individuais e investir nelas. De acordo com Chiavenato [5], as organizações que podem alcançar bons resultados serão aquelas que se dedicam a aprimoramento de pessoas, cultivando neles o comprometimento e a capacidade de aprender em todos os níveis da organização.

Treinamento \& Desenvolvimento, quando bem aplicado, trazer benefícios para as pessoas e organizações, como mostrado na Figura 11.



Figura 11 Quatro tipos de mudança de comportamento através de treinamento, de acordo com Chiavenato [5]. 


\subsection{A prática da ArcelorMittal Brasil - Aços Planos}

ArcelorMittal Brasil Aços Planos tem vários programas de desenvolvimento contínuo, que abrange todos os níveis de empregados, como administrativos, técnicos, especialistas, supervisores e gerentes. Para os especialistas, entre outras iniciativas, é importante destacar a pós-graduação, mestrado e doutorado, para alguns deles, organizado com algumas universidades chaves bem classificados no Brasil. Estes programas são apoiados por uma clara finalidade de negócios, a fim de melhorar algumas competências já identificadas e leva em consideração a meritocracia. Para exemplificar, a área de Redução da Usina de Tubarão tem em torno de $60 \%$ dos especialistas com pós-graduação, mestrado e doutorado concluídos.

\section{CONCLUSÕES}

Com base na discussão anterior, os seguintes aspectos são fundamentais para atingir operações sustentáveis e competitivas de uma Usina Siderúrgica Integrada:

- Manter controle apurado sobre a qualidade da matéria-prima. Certifique-se de que você está recebendo a qualidade acordado com o fornecedor;

- Estabelecer e manter os KPls dos processos sob controle severo; Não permita que grandes variações ocorram sem realizar uma análise de falha e implementar as contramedidas eficazes;

- Estimule a criatividade e a procura de alternativas que tragam soluções para resolver o problema;

- Foco na redução de custos com a estabilidade do processo;

- Tome um cuidado especial com a manutenção de seus ativos. Equipamentos bem cuidados são mandatórios para a otimização de processos;

- Desafie a desenvolva o seu pessoal; sempre existem boas ideias, recompense-os adequadamente e comemore os resultados.

\section{REFERÊNCIAS}

1 SANTOS, E. T. B.; COSTA, C. C; FUJIHARA, F. K., \& GUSHIKEN, J. I. - Implantation of the Central Coke Feeding Equipment in Blast Furnace \# 1 of CST - IAS 2005- 5th Ironmaking Conference Proceedings, 323-332

2 DEFENDI, G. A., Reaction kinetics of the characterization and behavior of the ashes of the burnt coal injected through the tuyeres of blast furnaces CST, -BH: UFMG, 2006. p.7-10. (Dissertation, Master of Science in Metallurgical Engineering)

3 MATHIESON, J. G. et., TRUELOVE, J., ROGERS, H. Toward an understanding of Coal Combus-tion in Blast Furnace Tuyere Injection. In: INTERNATIONAL SYMPOSIUM ON UTILIZATION OF COAL AND BIOMASS, 1, 2003, Newcastle.

4 SENGE, Peter M. The Fifth Discipline: The art and practice of the learning organization, Double-day, New York, Best Seller, 1990.

5 CHIAVENATO, Idalberto. People Management: the new role of human resources in organizations. 11th Edition. Rio de Janeiro: Campus, 1999 p.225.

6 McNAIR, Sam. "Budgeting for Maintenance: A Behavior-Based Approach". Lyfe Cycle Engineer-ing. 2011.

7 NOWLAN, F. Stanley and HEAP, Howard F., Reliability Centered Maintenance, United Airlines and Dolby Press, sponsored and published by the Office of Assistant Secretary of Defense, 1978. 